\title{
COMUNIDADES ECONÔMICAS NA PROTEÇÃO AOS DIREITOS HUMANOS: DESAFIOS E PERSPECTIVAS DE UMA AGENDA DE DIREITOS HUMANOS NA INTEGRAÇÃO REGIONAL
}

\author{
ECONOMIC COMMUNITIES IN THE PROTECTION OF HUMAN RIGHTS: \\ CHALLENGES AND PERSPECTIVES FOR A HUMAN RIGHTS AGENDA \\ IN REGIONAL INTEGRATION
}

\author{
Marina Feferbaum \\ FGV Direito SP (São Paulo, SP, Brasil)
}

Recebimento: 8 ago. 2016

Aprovação: 2 dez. 2016

\begin{abstract}
Como citar este artigo / How to cite this article (informe a data atual de acesso / inform the current date of access):
FEFERBAUM, Marina. Comunidades econômicas na proteção aos direitos humanos: desafios e perspectivas de uma agenda de direitos humanos na integração regional. Revista da Faculdade de Direito UFPR, Curitiba, PR, Brasil, v. 62, n. 1, jan./abr. 2017, p. 155 - 182. ISSN 2236-7284. Disponível em: <http://revistas.ufpr.br/direito/article/view/48004>. Acesso em: 30 abr. 2017. DOI: http://dx.doi.org/10.5380/rfdufpr.v62i1.48004.
\end{abstract}

\section{RESUMO}

Os arranjos econômicos regionais, que vêm ganhando fôlego desde o fim da Guerra Fria, têm incorporado, cada vez mais, temas de direitos humanos em suas agendas. Por isso, uma investigação das relações reais entre os direitos humanos e integração econômica é necessária para desnaturalizar uma ligação que normalmente se assume no âmbito do discurso. Este trabalho faz uma investigação ontológica, a partir de exercício argumentativo e dados da literatura, das implicações da inserção dessas agendas nas comunidades econômicas regionais. A primeira parte lida com o produto da integração econômica, testando os benefícios que ela pode trazer aos direitos humanos e o grau de certeza sobre seus resultados. A segunda parte enfoca o processo de integração, que congrega as relações entre os arranjos econômicos e as esferas da vida, e as escolhas sobre os direitos humanos que ocorrem de forma eventual ou planejada nos conflitos interníveis de ordenamentos jurídicos. Suas principais contribuições são traçar as potencialidades da promoção de direitos humanos por meio das comunidades econômicas regionais e chamar atenção para as consequências colaterais de quaisquer medidas integracionistas sobre os direitos humanos.

\section{PALAVRAS-CHAVE}

Integração econômica. Integração regional. Direitos humanos.

\begin{abstract}
Regional economic arrangements, that have been gaining momentum since the end of the Cold War, have been increasingly incorporating human rights matters in their agenda. Therefore, an ontological investigation of the real relations between human rights and economic integration, using argumentative exercise and data collected from the literature, is required to denaturalize a link that is usually assumed in the level of discourse. This paper investigates, in two steps, the implications of including these agendas in the regional economic communities. The first part deals with the product of economic integration, testing the benefits it can bring to human rights and the degree of certainty
\end{abstract}


about their results. The second part focuses on the integration process, that comprises both, the relations between the economic arrangements and spheres of life, and the choices about human rights that occur in planned or unplanned manners in the inter-level conflicts among legal orders. Its main contributions are to outline the potential of promoting human rights through regional economic communities and to draw attention to the side effects of any integrationist measures on human rights.

\section{KEYWORDS}

Economic integration. Regional integration. Human rights.

\section{INTRODUÇÃO}

Há quase setenta anos, a Declaração Universal dos Direitos do Homem inaugurava o paradigma contemporâneo da defesa internacional dos direitos humanos. Era o início do pós-Guerra, e a sociedade internacional entrava em uma fase de profunda transformação em razão da proliferação dos arranjos internacionais para lidar com questões de segurança, econômicas e políticas, frequentemente estruturados sob forma de organizações internacionais governamentais. Paralelamente, também houve a proliferação de organizações internacionais não governamentais e de empresas multinacionais, o que levou a sociedade civil e os mercados a se estabelecerem mundialmente. Os direitos humanos emergiram nesse cenário por meio dos chamados sistemas de defesa de direitos humanos, concebidos sob as estruturas dos grandes foros políticos internacionais nos moldes do paradigma da Declaração Universal.

Nas quatro décadas de Guerra Fria que se seguiram após a Segunda Guerra Mundial, os arranjos internacionais foram marcados pela forte influência (por vezes, ingerência) das grandes potências, incluindo criação da União Europeia (UE), então Comunidade Econômica do Carvão e do Aço (CECA), visto que o projeto econômico era uma estratégia para contenção da influência soviética e para a manutenção da paz na Europa Ocidental. Os arranjos econômicos eram ainda pouco comuns e frequentemente se misturavam com questões de segurança. Na Organização das Nações Unidas (ONU), no Conselho da Europa e na Organização dos Estados Americanos (OEA), os direitos humanos eram lentamente forjados pelas ideologias da Guerra Fria, que levou à cisão entre direitos civis e políticos e direitos econômicos sociais e culturais, formando, aos poucos, os primeiros sistemas de defesa.

No mesmo período, os movimentos panregionais se institucionalizam: o pan-árabe pela Liga Árabe, fundada em 1945, antes mesmo do fim da Segunda Guerra; e o pan-africano pela União Africana (UA), então Organização da Unidade Africana (OUA), fundada em 1963. O ideal de unificação regional desses movimentos fomentou o surgimento de arranjos sub-regionais sob a forma de comunidades econômicas, embora sem resultados relevantes - o sonho de redesenho do mapa 
africano, desfigurado pela Conferência de Berlim, por exemplo, não foi acompanhado pelo comprometimento político das soberanias recém-conquistadas (NALDI, 2002, p. 1). Na OUA, com um certo distanciamento cronológico e ideológico dos sistemas então existentes, os direitos humanos ganhavam contornos peculiares, com a ideia de direitos dos povos e sem a clássica cisão entre liberdades negativas e positivas.

Os arranjos internacionais foram, aos poucos, perdendo fôlego: os foros políticos eram impotentes perante os Estados Unidos e a União Soviética; as comunidades econômicas não avançavam em seus projetos de integração; a ONU era desacreditada em seu propósito internacional. Ao final da década de 1980, muitos duvidavam do potencial transformador das organizações internacionais (FAWCETT, 2003, p. 15-16).

O fim da Guerra Fria mudou bruscamente este cenário. Com o encerramento da disputa entre os EUA e a extinta URSS, muitos acordos militares e econômicos perderam a razão de existência, o que gerou um clima generalizado de insegurança econômica. Na busca de garantias, os Estados se mobilizaram para formar novos arranjos econômicos, o que levou à multiplicação de comunidades econômicas, inspiradas na fortaleza europeia erguida pelas Comunidades Europeias (CECA, ECC e Euratom), que avançavam para o Tratado de Maastricht (1992). A integração regional passou a ser vista como uma opção viável de proteção dos mercados diante das incertezas internacionais.

Diferentemente do ocorrido nas décadas anteriores, desde o início do séc. XXI tem-se notado o avanço dos direitos humanos para além das suas organizações intergovernamentais tradicionais. A pauta de direitos humanos atualmente faz parte da atuação de diversas comunidades econômicas regionais. Exemplos desse fenômeno são claros no Mercado Comum do Sul (Mercosul), na Associação do Sudeste Asiático (ASEAN) e na Comunidade Econômica dos Estados da África Ocidental (ECOWAS), para citar alguns.

No plano do discurso, a relação entre direitos humanos e a integração econômica regional encontra-se no objetivo último do estabelecimento da comunidade, que é o desenvolvimento humano. Afinal, para que integrar, senão para o benefício do Estado e, por conseguinte, do bem de seu povo? O motivo pelo qual os Estados buscam a integração é, certamente, a obtenção de algum benefício. Os tratados de fundação das comunidades atribuem esse benefício (qualquer que seja ele) ao bem de todos. E se o benefício for o aumento de riqueza do país, é possível que ele seja acompanhado de aumento de ofertas de emprego, melhoria de renda para alguns setores, etc., podendo, ao final, resultar em melhoria dos indicadores associados ao bem-estar da população. É razoável supor que a integração possa ser uma boa estratégia para o desenvolvimento do país. Contudo, é necessário desnaturalizar uma relação necessária entre a integração e a efetivação dos direitos humanos. 
Atualmente, analisar por completo as características da proteção aos direitos humanos nas comunidades econômicas regionais envolve ao menos duas análises distintas: uma sobre a relação entre direitos humanos e a integração econômica (com destaque para o seu processo e seu produto) e outra sobre a adoção de uma agenda protetiva de direitos humanos decorrente de uma escolha política. O objetivo deste artigo é explorar a primeira delas. Analisaremos a seguir como o estabelecimento da comunidade e seu processo de integração impacta nos direitos humanos, positiva e negativamente, independentemente de uma política voltada ao seu fomento. Isoladamente, o aprofundamento dessa análise lança luz às relações práticas entre desenvolvimento econômico e direitos humanos, utilizando exemplos positivos e negativos do trabalho institucional das comunidades econômicas regionais.

O artigo tem duas partes, que serão pautadas pela investigação ontológica da relação entre a integração econômica e a promoção dos direitos humanos no processo e no produto das comunidades econômicas regionais, a partir de exemplos e dados coletados de outras produções sobre o tema. Utilizaremos a diferença entre processo e produto para distinguir o caminho da dinâmica de integração (processo), daquilo que a integração almejou alcançar ou alcançou (produto). A primeira parte, sobre o produto da integração, investigará se há algum indício de relação necessária entre a integração econômica e a implementação de direitos humanos, de um ponto de vista ontológico. Duas perspectivas de análise integrarão uma argumentação baseada em conceitos e exemplos da prática institucional das comunidades econômicas regionais. O primeiro elemento é a possível ligação entre a integração de mercados, levando em conta seus benefícios a indivíduos, e a expansão dos seus direitos humanos. O segundo elemento será a performance do mercado integrado, o modo como é medido seu sucesso ou fracasso, e a relação dessa mensuração com o objetivo indireto de promoção dos direitos humanos.

Na segunda parte, sobre o processo da integração, será discutida a ligação entre o arranjo econômico e as várias outras áreas da vida, e como isso se reflete no processo de integração quando observados os conflitos normativos entre ordenamentos. Ainda nesta parte, serão investigados casos da jurisdição comunitária, diante da escolha por proteger ou não os direitos humanos como aplicáveis a partir dos próprios ordenamentos nacionais dos Estado partes da integração econômica.

\section{O OBJETO DA INTEGRAÇÃO E SUAS RELAÇÕES COM DIREITOS HUMANOS}

A integração econômica regional é, antes de tudo, a integração dos mercados nacionais num mercado mais amplo, parcial ou total. É derrubar barreiras jurídicas de certos bens para facilitar negócios entre os Estados participantes (em zona de comércio preferencial ou em zona de livre 
comércio), fazendo-se, quando necessário, a padronização dos negócios extracomunitários por meio de uma tarifa externa comum. Se for de interesse, estabelece-se a livre circulação de bens, de serviços, de capital e de força de trabalho (i.e., de pessoas), formando-se um mercado único. Conforme a teoria de spillover $^{1}$, a implantação de um nível de integração acaba promovendo a integração de outros setores, como a formulação de uma política econômica comum (união econômica) e adoção de moeda única para viabilizar o mercado comunitário. Ou seja, o objeto da integração regional é a integração de mercados, o que envolve, além da integração econômica, a integração política, a qual varia conforme a profundidade da primeira (i.e, da integração econômica).

Assim, o objeto da integração, aquilo que resulta do seu processo de integração políticoeconômica, é a integração de mercados. Quaisquer outros resultados são contingentes e constituem o que se espera obter da integração dos mercados. Pode-se, consequentemente, separar os objetivos da integração em objetivos diretos (ou imediatos) - que são as transformações (ou a performance) esperadas do objeto - e objetivos indiretos (ou mediatos) - que são os efeitos esperados dessa transformação. De acordo com essa visão, a ampliação do mercado nacional, por exemplo, é um objetivo direto da integração que leva aos objetivos indiretos de aumento da oferta de emprego e de melhoria na distribuição de renda.

Conceber o projeto de integração dessa maneira permite situar melhor os diferentes objetivos em relação ao processo. É preciso então analisar como os direitos humanos se relacionam com o objeto, com os objetivos diretos e com os objetivos indiretos.

\subsection{INTEGRAÇÃO DE MERCADOS E O AUMENTO DE DIREITOS DOS INDIVÍDUOS}

A relação entre direitos humanos e a integração de mercados (objeto da integração) pode ser analisada pelo impacto da ampliação do mercado nacional nesses direitos, independentemente da performance do novo mercado. Ou seja, quais resultados positivos ou negativos a eliminação de barreiras comerciais produz nos direitos humanos.

De plano, a liberação de barreiras comerciais produz um desequilíbrio no mercado nacional, na medida em que bens produzidos com maior eficiência nos mercados recém-integrados podem

\footnotetext{
${ }^{1}$ A teoria indica que o nível de integração entre Estados pode ser localizado em uma escala que vai de nenhuma integração - em que cada Estado é absolutamente autônomo - e integração absoluta - em que se cria um novo Estado a partir de um grupo deles. Cf. HASS, 1958 apud MCCORMICK, OLSEN, 2014, pos. 859/8323 (versão e-book); LINDBERG, 1963 apud MCCORMICK, OLSEN, 2014, pos. 859/8323. Para as divisões em etapas variadas criadas pela literatura, cf. MCCORMICK, OLSEN, 2014, pos.892-908/8323; VILJOEN, 2012, p. 485.
} 
tornar os similares nacionais menos competitivos, levando-o a uma perda de participação, com consequente diminuição da oferta de emprego, entre outros fatores. Contudo, a situação inversa também pode acontecer nos demais mercados com relação a outros bens, levando a um ganho de espaço. Na média, um Estado pode sair ganhando, embora o resultado seja de difícil mensuração, visto que há muitas variáveis afetadas. Um exemplo é a oferta de emprego, que, mesmo diante de um resultado positivo, pode aumentar para a mão de obra qualificada ao custo da diminuição para a desqualificada. A consequência é a exclusão dos menos qualificados do mercado de trabalho e maior carga para o sistema previdenciário, já que as chances de recolocação diminuem. Mesmo neste caso, é difícil quantificar o prejuízo aos direitos humanos ao mesmo modo de casos que resultassem em exclusão social ou em formas de privação de liberdade, por exemplo.

Outra consequência da integração dos mercados, a depender da profundidade da integração, é a diminuição ou eliminação das barreiras ao trânsito de pessoas. Do ponto de vista econômico, essa medida integra os mercados de trabalho, permitindo o fluxo de mão de obra entre os Estados participantes. Tal benefício é atribuído aos cidadãos de tais Estados, não contemplando os estrangeiros extracomunitários. Por essa razão, a medida não é sinônimo de eliminação de controles de fronteira. Os efeitos da implantação de trânsito facilitado ou de livre trânsito de pessoas vão além da ampliação do espaço de circulação. É necessário conferir aos cidadãos todo um conjunto de direitos que sustentem essa liberdade, a começar pelos direitos trabalhistas, de seguridade social, de saúde e de educação, sem os quais os trabalhadores comunitários estariam desamparados no espaço integrado que vai além do território de suas nações de origem. Outros direitos também costumam entrar na lista, tais como direitos políticos, direitos consulares, padronização de documentos de identificação, além do acesso a transporte, comunicação e transferência de valores.

O MERCOSUL, por exemplo, “que pode ser caracterizado como uma união aduaneira em fase de consolidação, com matizes de mercado comum” (BRASIL, [20--]), adotou nesse sentido um Estatuto da Cidadania do MERCOSUL - que consiste em um plano de ação para estabelecer normas sobre circulação de pessoas, fronteiras, identificação, documentação e cooperação consular, trabalho e emprego, previdência social, educação, transporte, comunicações, etc. - e já conta com trânsito facilitado de pessoas pelos Estados partes de dois acordos do bloco ${ }^{2}$, com direito de solicitação de residência legal, a partir da qual "têm habilitação para trabalhar em igualdade de condições que os nacionais destes Estados” (BRASIL, [20--]), permitida a unificação das “contribuições e

\footnotetext{
${ }^{2}$ Acordo sobre Residência para os Nacionais dos Estados Parte do MERCOSUL (MERCOSUL, 2002a) e Acordo sobre Residência para os Nacionais dos Estados Partes do MERCOSUL, Bolívia e Chile (MERCOSUL, 2002b).
} 
recolhimentos feitos à Seguridade Social pelos trabalhadores migrantes para fins da obtenção dos benefícios previdenciários” (BRASIL, [20--]).

Para o indivíduo, o direito de se estabelecer em qualquer lugar do espaço comunitário também possui outros significados. Pelo menos em teoria, a possibilidade de procurar trabalho em outros mercados nacionais significa aumento de oportunidades, ampliando sua esfera de liberdade. Na prática, porém, pode haver mais do que barreiras jurídicas, tais como barreiras linguísticas, sociais e culturais, de maneira que, dependendo da realidade e do contexto locais, o espaço comunitário pode estar bem distante de um espaço nacional aumentado. Ainda assim, pela ótica daqueles que já se encontram em outro Estado do bloco, tal direito é uma garantia de liberdade, na medida em que "os migrantes e os membros de suas famílias são [...] protegidos contra expulsão coletiva ou arbitrária de um país parceiro” (VILJOEN, 2012, p. 497, tradução nossa), particularmente quanto à livre circulação de pessoas estabelecida em 1979 na CEDEAO (ECOWAS).

Na implantação de um mercado comum, no qual o livre trânsito compreende pessoas, bens, serviços e capital, há ainda outros possíveis benefícios para os indivíduos. "Na região da CEEAC, onde quatro países sem saída para o mar dependem de hidrovias e portos de outros estados, a livre circulação ganha importância adicional” (VILJOEN, 2012, p. 497, tradução nossa), por exemplo. Além do óbvio benefício de acesso facilitado ao mar e aos portos em razão de fatores como a desnecessidade de controle aduaneiro dos bens em passagem pelo território do país costeiro, que não ocorreria com a mesma facilidade no caso de um tratado entre os dois países sobre permissão de passagem, há, pelo menos por parte dos Estados encravados, genuíno interesse no sucesso da empreitada comunitária e em manter boas relações com os parceiros em razão da dependência resultante, podendo a integração servir de instrumento para a consecução da paz.

Em si, a integração de mercados, especificamente com relação ao livre trânsito e domicílio de pessoas, amplia, em tese, a esfera de liberdade instrumental do indivíduo, particularmente com relação ao trabalhador migrante, como apontado acima. Mas isso não implica a correlação entre integração de mercados e fomento aos direitos humanos, na medida em que há outras questões contingentes envolvidas, como a possibilidade de gerar exclusão.

\subsection{INTEGRAÇÃO REGIONAL E DIREITOS HUMANOS: UMA RELAÇÃO COMPLEXA}

A análise da relação entre direitos humanos e a performance do mercado integrado parte da hipótese de que este transforme o mercado nacional da maneira esperada, ou seja, atingindo os objetivos imediatos da integração, entre os quais o desenvolvimento, principalmente o econômico. É 
particularmente tentador considerar a correlação desse último objetivo com os direitos humanos, adotando-se a premissa de que o desenvolvimento econômico seria uma forma de desenvolvimento social, o qual é sempre positivo aos direitos humanos. Afinal, uma economia mais desenvolvida significa maior abundância de oportunidades, postos de trabalho, serviços, arrecadação de tributos, etc., que podem contribuir para o bem-estar dos indivíduos.

Contudo, se adotado o conceito de desenvolvimento como liberdade formulado por Amartya Sen (2000), a premissa deve ser afastada, já que, a despeito de poder contribuir para o desenvolvimento humano, o desenvolvimento econômico não é sinônimo deste último, principalmente se pautado em mecanismos de mercado puro ${ }^{3}$. Isso porque “a utilidade da riqueza está nas coisas que ela nos permite fazer - as liberdades substantivas que ela nos ajuda obter” (SEN, 2000, p. 28) -, observado que “essa relação não é exclusiva [...] nem uniforme” (SEN, 2000, p. 28), além de não haver certeza quanto ao resultado. Ainda que o desenvolvimento econômico seja importante para o desenvolvimento humano, e este para os direitos humanos, a relação entre os três não é necessária.

Pensar no desenvolvimento como “um processo de expansão das liberdades” (SEN, 2000, p. 17), e não como desenvolvimento econômico, coloca ênfase naquilo que efetivamente as formas de desenvolvimento devem propiciar. Este se torna importante àquele enquanto cumprir o papel de expansão das liberdades. Numa hipótese de insucesso nesse âmbito, a política econômica de um governo se torna questionável. Ou seja, a relação entre a performance do mercado integrado e os direitos humanos não é evidente, devendo-se analisá-la mais a fundo.

Partindo-se da hipótese de que o almejado desenvolvimento econômico seja alcançado, por exemplo, pela elevação do produto interno bruto (PIB), o impacto no bem-estar da população requer dados adicionais: houve maior distribuição de riqueza, diminuição das desigualdades, diminuição do desemprego, maior acesso à saúde e à educação? Tais questões representam uma ínfima parcela de variáveis do cenário real. Por exemplo, mesmo em um cenário de crescimento econômico que tenha promovido maior concentração de riquezas, a distribuição de uma parcela desse crescimento, ainda que desproporcionalmente menor, poderia retirar famílias da situação de miséria, diminuindo os índices de pobreza extrema. O desenvolvimento econômico pode beneficiar os direitos humanos ou o desenvolvimento social, embora não necessariamente, e, concomitantemente, gerar resultados

\footnotetext{
${ }^{3}$ Construção elaborada a partir das ideias e termos de Sen, mas representando sentido diferente do adotado pelo autor. A expressão "mecanismos de mercado puro" é utilizada no sentido do senso comum intelectual sobre o mercado, e não de sua relação com o desenvolvimento humano (SEN, 2000, p. 135-136).
} 
negativos, como o aumento de desigualdades. Logo, se o desenvolvimento econômico é o objetivo imediato da integração, alcançá-lo não é garantia de retorno social.

A distinção entre objetivos diretos e indiretos vai além das incertezas quanto aos resultados, já que os últimos são igualmente difíceis de avaliar. O caso da Comunidade Europeia da Energia Atômica (EURATOM), por exemplo, parece ter no seu objeto (de criar uma comunidade de energia atômica) uma relação ambígua com sua missão de melhoria do nível de vida nos Estados membros. No preâmbulo e nos dois primeiros artigos do seu tratado constitutivo (abaixo reproduzidos da versão consolidada em português, mas sem alterações nessa parte do texto original de 1957), os diversos objetivos se relacionam como se decorressem logicamente uns dos outros.

Por sua natureza não dispositiva, o preâmbulo traz a camada de discurso do diploma, a visão política da empreitada. $\mathrm{O}$ artigo $1^{\circ}$ estabelece o objetivo imediato - a “formação e crescimento rápido das indústrias nucleares” - juntamente com os objetivos mediatos de "melhoria do nível de vida nos Estados-Membros” e “o desenvolvimento das relações com os outros países”. O artigo $2^{\circ}$ detalha o objeto - “criação de um mercado comum de materiais e equipamentos especializados” de energia nuclear - e traz algumas diretrizes, dentre as quais a $h$, pela qual o segundo objetivo mediato deve ser alcançado. O primeiro objetivo mediato - “a melhoria do nível de vida nos Estados-Membros” - não possui disposição específica à sua consecução, sendo ou presumida em função do sucesso do acordo, ou estabelecida como valor a ser seguido no processo de integração (UNIÃO EUROPEIA, 2010, p. 5-7).

Não há dúvidas da importância estratégica da empreitada em dominar uma fonte de energia alternativa aos combustíveis fósseis e ao potencial hidrelétrico, ou do desenvolvimento de um parque energético com potencial elétrico para acompanhar o desenvolvimento industrial, além do conhecimento adquirido no processo, possibilitando sua aplicação em outras áreas como a medicina. Contudo, que tudo isso seja causa de melhoria do nível de vida das pessoas é de difícil mensuração, principalmente em razão do perigo do combustível nuclear para a vida em caso de desastre.

À época, o mundo ainda não havia experimentado o acidente de Three Mile Island, nos EUA em 1979, de Chernobyl, em 1986 (IAEA, 2015), ou o de Fukushima, em 2011 (IAEA, 2016) - os dois últimos alcançando a categoria máxima (7) na Escala Internacional de Eventos Nucleares e Radiológicos (INES) (IAEA, [20--]), mas o perigo era conhecido, conforme os artigos 30 a 39, entre outros, que refletem a preocupação em estabelecer parâmetros e padrões para operação segura do combustível nuclear. Em 1957, ou seja, antes mesmo da entrada em vigor da EURATOM (que aconteceu em 1/1/1958), ocorrera um acidente em Kyshtym, na Rússia, com “significante liberação de material radioativo no meio ambiente da explosão de um tanque de resíduos altamente ativos” 
(IAEA, [20--] $)^{4}$, evento de categoria 6 na escala INES, considerado grave, com necessidade de implementação de contramedidas planejadas.

O perigo e a controversa empreitada levaram ao surgimento de movimentos contrários à geração termonuclear na Alemanha durante a década de 1970 (APPUNN, 2015, p. 1). Os grandes acidentes influenciaram a decisão do país de desativar seu parque energético nuclear até 2022 (APPUNN, 2015, p. 1). Ressalta-se que a própria Comunidade conta com um histórico de acidentes e incidentes em usinas nucleares (ROGERS, 2011). Por outro lado, a EURATOM possui atualmente “programas de assistência de desativação para ajudar a Bulgária, a Lituânia e a Eslováquia a financiar a desativação segura de antigos reatores soviéticos” (EUROPEAN COMISSION, [2016]) ${ }^{5}$, contribuindo para a segurança do processo nesses novos membros. De todo modo, "a melhoria do nível de vida”, se não presumida, parece ter mais uma qualidade discursiva do que dispositiva ou axiológica, a despeito de constar do rol normativo.

Há, no entanto, a ressalva referente à estreita relação da Comunidade com a CECA e a CEE, o que remete à estratégia de pacificação europeia por meio do enlace dos mercados, buscando, nesse sentido, a melhoria do nível de vida. Nesse cenário, porém, o resultado decorre da mútua dependência decorrente do acordo (com relação ao objeto da integração), e não da indústria nuclear e da performance do seu mercado.

Um caso bastante diverso é o da Autoridade Intergovernamental para o Desenvolvimento (Intergovernmental Authority on Development, IGAD), que surgiu com a missão precípua de combate às frequentes fomes coletivas que ocorriam no Chifre da África. Inicialmente denominada Autoridade Intergovernamental para a Seca e o Desenvolvimento (IGADD), foi "formada em 1986 com o limitado mandato sobre assuntos de seca e desertificação” (UNESCO, [201-?], tradução nossa) .

As recorrentes e severas secas e outros desastres naturais entre 1974 e 1984 causou fomes coletivas, degradação ecológica e dificuldades econômicas generalizadas na região da África Oriental. Apesar dos esforços substanciais individuais dos países para lidar com a situação e dos generosos apoios da comunidade internacional, a magnitude e extensão do problema clamava por uma análise regional para suplementar os esforços nacionais.

Em 1983 e 1984, seis países no Chifre da África - Djibuti, Etiópia, Quênia, Somália, Sudão e Uganda - tomaram medidas por meio das Nações Unidas para estabelecer uma organização

\footnotetext{
${ }^{4}$ Tradução livre de: "Significant release of radioactive material to the environment from explosion of a high activity waste tank” (IAEA, [20--]).

${ }^{5}$ Tradução livre de: "The EU has set up nuclear decommissioning assistance programmes to help Bulgaria, Lithuania, and Slovakia finance the safe decommissioning of old Soviet-type reactors” (EUROPEAN COMISSION, [2016]).

${ }^{6}$ Tradução livre de: “The Intergovernmental Authority on Drought and Development (IGADD) was formed in 1986 with a very narrow mandate around the issues of drought and desertification” (OPEN SOCIETY INSTITUTE, 2003).
} 
intergovernamental para o desenvolvimento e o controle das secas na região. (IGAD, 2010, p. 1 , tradução nossa) ${ }^{7}$

Desde sua criação, a organização tornou-se um foro de diálogo para questões de segurança e política regionais, o que levou à ampliação de seu mandato em 1995, transformando a IGADD em IGAD. Entre seus objetivos estavam:

a) Promover estratégias conjuntas de desenvolvimento e gradualmente harmonizar políticas macroeconômicas e programas nas áreas social, tecnológica e científica; b) [...] promover a livre circulação de bens, serviços e pessoas e a fixação de residência; c) Criar um ambiente apto a negócios e investimentos estrangeiros, transfronteiriços e domésticos; d) Alcançar segurança alimentar e encorajar e assistir esforços dos Estados membros a combater a seca e outros desastres naturais e provados e suas consequências; e) Começar e promover programas e projetos para o desenvolvimento sustentável de recursos naturais e proteção ambiental; f) Desenvolver e melhorar uma infraestrutura complementar e coordenada, particularmente nas áreas de transporte e energia; g) Promover a paz e a estabilidade na subregião e criar mecanismos dentro da sub-região para prevenção, gerenciamento e resolução de conflitos inter e intraestatal por meio de diálogo [...]. (IGAD, 1996, p. 7, grifo nosso) ${ }^{8}$

A organização intergovernamental, que nasceu com objetivo político, transformou-se em comunidade econômica na reforma de 1995, para o estabelecimento de um mercado comum, preservando, contudo, sua missão original. De fato, o novo projeto reafirma o combate à fome, à seca e à desertificação, estabelecendo cooperação em diversas áreas correlatas, conforme o disposto no artigo 13A, alíneas $a$ a $h$ e $q$ a $t$. Com a ampliação do mandato, contudo, também foram contempladas as áreas de comércio, eliminação de barreiras tarifárias e não tarifárias, harmonização de infraestrutura de transporte e comunicação, harmonização das políticas fiscais e monetárias, política de fomento a investimentos internos e externos, política de desenvolvimento energético, harmonização das políticas científica e tecnológica, estabelecimento do mercado comum e promoção de intercâmbio social e cultural (alíneas $j$ a $p$ ).

\footnotetext{
${ }^{7}$ Tradução livre de: "The recurring and severe droughts and other natural disasters between 1974 and 1984 caused widespread famine, ecological degradation and economic hardship in the Eastern Africa region. Although individual countries made substantial efforts to cope with the situation and received generous support from the international community, the magnitude and extent of the problem argued strongly for a regional approach to supplement national efforts. In 1983 and 1984, six countries in the Horn of Africa - Djibouti, Ethiopia, Kenya, Somalia, Sudan and Uganda took action through the United Nations to establish an intergovernmental body for development and drought control in their region" (IGAD, 2010).

${ }^{8}$ Tradução livre de: "a) Promote joint development strategies and gradually harmonize macro-economic policies and programmes in the social, technological and scientific fields; b) [...] promote free movement of goods, services, and people and the establishment of residence; c) Create an enabling environment for foreign, cross-border and domestic trade and investment; d) Achieve regional food security and encourage and assist efforts of Member States to collectively combat drought and other natural and man-made disasters and their consequences; e) Initiate and promote programmes and projects for sustainable development of natural resources and environment protection; f) Develop and improve a coordinated and complementary infrastructure, particularly in the areas of transport and energy; g) Promote peace and stability in the sub-region and create mechanisms within the sub-region for the prevention, management and resolution of inter and intra-State conflicts through dialogue; [...]" (IGAD, 1996).
} 
No papel, a IGAD é o aprimoramento da IGADD, cujo legado foi a criação de um Sistema de Alerta Precoce e de Informação de Alimentos para Segurança Alimentar (EWFIS), estabelecido em 23 de janeiro de 1989 em acordo celebrado entre a IGADD, a Itália e a Food and Agriculture Organization of the United Nations (FAO), e desenvolvido entre 1991 e 1996 (FAO, 1997). O projeto foi concebido para “fornecer informações antecipadas sobre produção agrícola e animal e abastecimento de alimentos, e alertar com boa antecedência a escassez e excesso iminentes para a adoção oportuna de medidas preventivas” (FAO, 1997) ${ }^{9}$. Seu produto foi o desenvolvimento de modelos, matemáticos e de dados, consolidados em software e banco de dados para apoio às unidades nacionais de alerta precoce de segurança alimentar já existentes, de modo a suprir suas carências, particularmente as de natureza técnica.

Um relatório da FAO de 1997 sobre o Sistema Regional de Alerta Precoce e de Informações de Alimentos da IGAD (EWFIS) apontou problemas desde seu estabelecimento, com mais de um ano de atraso para que se tornasse plenamente operacional (de setembro de 1989 para janeiro de 1991) e inconsistências no projeto original, cuja revisão, aprovada em 1992, "chegou tarde demais para que as atividades originalmente contempladas fossem cumpridas” (FAO, 1997, tradução nossa). A despeito da sua contribuição no desenvolvimento das metodologias de alerta precoce, o desenvolvimento concomitante de software e metodologia tornou impossível a distinção entre ambos, além de concessões metodológicas em favor de aspectos do sistema, o que repercutiu negativamente na sua adoção por alguns Estados membros (FAO, 1997). Ao final, “embora a decisão original da IGADD de implementar um sistema regional tenha sido adequada, a situação no nível nacional fez dela demasiadamente otimista” (FAO, 1997, tradução nossa) ${ }^{10}$, agravada pela inexistência de uma estrutura institucional dedicada ao projeto.

Em 2010-2011, a maior seca dos últimos 60 anos do Chifre da África e conflitos na Somália levaram a região a uma nova crise alimentar, afetando mais de 13 milhões de pessoas ${ }^{11}$. Em resposta, a Cúpula dos Chefes de Estado e de Governo da IGAD e da EAC, reunida em Nairóbi em 9/11/2011, “tomou a ousada decisão de enfrentar as recorrentes secas nas comunidades vulneráveis da região da IGAD, pedindo maiores comprometimento dos países afetados e investimentos dos associados”

\footnotetext{
${ }^{9}$ Tradução livre de: “The project was expected to provide advance information on crop and animal production and food supply and to alert those concerned well in advance of impending food shortage and surplus so that timely and remedial action could be taken as appropriate".

10 Tradução livre de: "Although the original IGADD decision to implement a regional system was appropriate, the situation at national level made it far too optimistic".

${ }^{11}$ Uma descrição da situação vivida na região pode ser encontrada no site do World Food Programme [2016?].
} 
(IGAD, 2013, p. 9, tradução nossa) $)^{12}$. O resultado foi a criação da Iniciativa da IGAD para a Resiliência e Sustentabilidade (IDDRSI) ante os desastres decorrentes de seca, com uma visão holística do problema, compreendo sete áreas prioritárias:

(1) Gestão de recursos naturais e ambiental: [...] (2) Acesso ao mercado, comércio e serviços financeiros [...] (3) Apoio à subsistência e serviços sociais essenciais [...] (4) Gestão de risco de desastres, prontidão e resposta efetiva[...] (5) Pesquisa, gestão de conhecimento e transferência de tecnologia [...] (6) Prevenção e resolução de conflito e promoção da paz $[\ldots]$ (7) Coordenação, fortalecimento institucional e parcerias $[\ldots]^{13}$ (IGAD, 2013, p. 25, grifo nosso).

O escopo do novo projeto é bastante amplo, abrangendo, de maneira sucinta, meio ambiente, integração regional, economia de subsistência, desastres climáticos, pesquisa, conflitos armados e estrutura institucional. A IDDRSI é ainda muito recente para uma análise de sua efetividade. No entanto, sua existência já representa uma mudança de paradigma em relação ao EWFIS de 1989, enfrentando a crise alimentar como problema multidisciplinar e estrutural que exige comprometimento político, não como uma simples condição climática que afeta a produção e oferta local de alimentos, possivelmente identificável por modelos matemáticos.

Se tivesse dado certo, é provável que a utilidade do EWFIS estaria restrita à aceleração de medidas de contenção, não servindo para resolver o problema na sua raiz. Conforme observa Sen (2000, p. 189), “para eliminar a fome no mundo moderno é crucial entender a causação das fomes coletivas de um modo mais amplo, e não apenas em função de algum equilíbrio mecânico entre alimento e população”. Sobre isso, o autor considera que:

[...] Um trabalhador pode ser levado a passar fome devido ao desemprego, combinado com a ausência de um sistema de seguridade social que forneça recursos como o segurodesemprego. Isso pode facilmente acontecer e, de fato, uma grande fome coletiva pode sobrevir apesar de um nível geral elevado ou até mesmo de um "pico” na disponibilidade de alimentos. [...]

Mesmo quando uma fome coletiva está associada a um declínio na produção de alimentos [...], precisamos ir além das estatísticas de produção para explicar por que alguns segmentos são dizimados enquanto o restante nada sofre. [...] (SEN, 2000, p. 194-196)

Se o problema do Chifre da África não se resume às crises de produção de alimentos, a IDDRSI é mais adequado que o EWFIS para enfrentar o problema das secas, tratando cada uma das

\footnotetext{
12 Tradução livre de: "The Summit took the bold decision to address the effects of recurring droughts on vulnerable communities in the IGAD region, calling for increased commitment by affected countries and Development Partners to support investments in sustainable development especially in the Arid and Semiarid Lands (ASALs).” (IGAD, 2013, p. 9) 13 Tradução livre de: “(1) Natural resources and environment management [...] (2) Market access, trade and financial services [...] (3) Livelihoods support and basic social services [...] (4) Disaster risk management, preparedness and effective response [...] (5) Research, knowledge management and technology transfer [...] (6) Conflict prevention, resolution and peace building [...] (7) Coordination, institutional strengthening and partnerships [...]” (Ibid., p. 25).
} 
áreas prioritárias do seu projeto a partir do problema da insegurança alimentar. Nesse sentido, a IDDRSI tornou-se aquilo que a IGADD deveria ser, mas nunca conseguiu. Pode-se afirmar que a razão de seu fracasso foi, em certo sentido, a transformação da IGADD em IGAD, o que deixou o combate à insegurança alimentar em segundo plano. Paradoxalmente, o desenvolvimento econômico é, segundo Sen, um passo necessário à solução das crises alimentares na África subsaariana, o que faria da integração econômica (e, portanto, da IGAD) uma aposta teoricamente melhor para lidar com o problema do que arranjos de cooperação política (como foi a IGADD):

\begin{abstract}
A expansão econômica frequentemente reduz a necessidade de proteção de intitulamentos, e além disso aumenta os recursos disponíveis para fornecer essa proteção. Essa é uma lição importante para a África subsaariana, onde a ausência de um crescimento econômico global tem sido uma importante fonte básica de privação. A propensão às fomes coletivas é muito maior quando a população é generalizadamente pobre e quando é difícil obter fundos públicos. [...] No que concerne à falta de crescimento, a característica principal da África subsaariana não é especificamente a ausência na produção de gêneros alimentícios, mas a ausência geral de crescimento econômico (da qual o problema da produção de alimentos é apenas uma parte). (SEN, 2000, p. 205-206)
\end{abstract}

Na realidade, a IGADD (de 1986) já nasceu como uma semente da IGAD (de 1995). A reforma de 1995 apenas chancelou o uso do primeiro como foro de discussão de assuntos regionais diversos, que sempre integraram as pautas das suas reuniões institucionais. A adoção de uma agenda concreta de integração econômica, a verdadeira inovação, foi concebida em coordenação com a COMESA (estabelecida em 1992), da qual quase todos os membros da IGAD fazem parte. O inciso i do Artigo 7 do Acordo de 1995 dispõe a intenção de "promover e realizar os objetivos do Mercado Comum para a África Oriental e Austral (COMESA) e a Comunidade Econômica Africana”, revelando a pretensão de seu projeto de, eventualmente, fundir-se a essas comunidades, a começar pela COMESA, que forma, juntamente com EAC e SADC, a chamada Tripartite Task-Force (COMESA-EAC-SADC TRIPARTITE, 2010), com a qual já há diálogo de harmonização de programas de desenvolvimento, a exemplo da Conferência de Desenvolvimento de Infraestrutura COMESA-EAC-SADC-IGAD, realizada em outubro de 2010 em Nairóbi (COMESA-EAC-SADC TRIPARTITE; IGAD, 2010).

O envolvimento da IGAD com o projeto de integração regional, inclusive no que concerne à pretensão panafricanista, tem evoluído consistentemente. O mesmo não se deu com relação à missão de combate à fome coletiva, que só passou a ser encarada seriamente apenas a partir da crise de 20102011. Ou seja, foi a falta de esforços em enfrentar o problema da insegurança alimentar a razão do insucesso nesta área, e não o arranjo de integração econômica, cujo tratado jamais deixou de lado a missão original da IGADD. 
Conforme consta do preâmbulo do acordo de 1995, é possível que a decisão de se "buscar uma cooperação mais abrangente fundada na igualdade e mútuo benefício para alcançar integração econômica" esteja, além de outros, fundada na "necessidade de esforços concentrados em combater a seca e outros desastres naturais e causados pelo homem”, concebendo a integração como condição para alcançar os objetivos da IGADD. É provável, no entanto, que a reforma de 1995 seja evidência de que assuntos relacionados ao desenvolvimento econômico sempre prevaleceram sobre aqueles relacionados à cooperação para resolver o problema da insegurança alimentar da região, e que, talvez, houvesse crença de que esse desenvolvimento econômico seria, sozinho, a solução final.

Não é o caso de negar as importantes conquistas e atuações da IGAD em diversas áreas, como a busca pela solução de conflitos, que, entre outros, levou ao estabelecimento em 2002 do Alerta Precoce e Mecanismos de Resposta a Conflitos (CEWARN), que tem operado com sucesso desde então. Contudo, o quarto de século da criação da IGADD e a década e meia da sua transformação em IGAD pouco fizeram para evitar a crise alimentar de 2010-2011. A conversão da IGADD em IGAD significou, em última análise, um desvio na finalidade original da primeira, e, nesse sentido, representou o fracasso de seu principal objetivo, ao mesmo tempo que criou condições mais aptas a implementá-lo.

A grande oportunidade para retomar os trabalhos da IGADD foi a crise de 2010-2011, que exigiu da comunidade uma nova postura ante o problema alimentar, que resultou na IDDRSI. A mudança de paradigma é particularmente evidente na Área Prioritária 2, referente à integração econômica, a qual é tratada como instrumento (coadjuvante) no combate à fome coletiva - por exemplo, por meio de regulação comunitária sanitária e fitossanitária apta a assegurar um padrão de saúde de lavouras e rebanhos, do desenvolvimento do comércio e dos serviços financeiros. De um lado, tal tratamento associa-se à ideia de que a integração precisa ser conduzida por meio de políticas específicas para que possa alcançar determinados resultados. De outro, ela não rejeita que o desenvolvimento do mercado possa contribuir para uma maior resiliência aos efeitos das secas, devendo reputar-se área prioritária. Em outras palavras, embora não seja a solução para o problema, o desenvolvimento econômico é um importante instrumento para a sua consecução; apenas não o é sozinho, dependendo de políticas públicas destinadas ao enfrentamento do problema.

Mais do que um novo paradigma, a IDDRSI representa também um comprometimento completamente diferente. Comparativamente, o EWFIS de 1989 contou com pouco mais de US\$ 6 milhões e tinha como objetivo o desenvolvimento de um software para ser utilizado pelos Estados no monitoramento da situação alimentar; a IDDRSI, por sua vez, é uma estrutura institucional dedicada e permanente estimada em US\$ 300 milhões (IDDRSI, 2015), que visa enfrentar o problema por sete 
áreas prioritárias, entre as quais a referida pelo item 4, referente à gestão de desastres. Chama atenção particularmente o item 4.1, que sugere o desenvolvimento de um EWFIS mais robusto, possivelmente nos moldes do CEWARN, e representa apenas um entre mais de trinta itens de trabalho. Independentemente dos resultados que venha a alcançar, o desenho da IDDRSI exprime a consciência de que a consecução de objetivos no âmbito comunitário exige esforços efetivos da comunidade e dos membros, não bastando a integração de mercados e eventual desenvolvimento econômico.

O que o exemplo da IGAD nos indica é que o desenvolvimento econômico pode ser parte da consecução de objetivos relacionados ao desenvolvimento humano e aos direitos humanos, principalmente em regiões de extrema pobreza, onde o mercado é subdesenvolvido e prevalece economia de subsistência, o que torna as comunidades vulneráveis a perturbações. Mesmo nesses casos, permanece a necessidade de políticas específicas e direcionamento da integração, não havendo correlação entre performance de mercado pautada em mecanismos de mercado puro e desenvolvimento humano e/ou direitos humanos.

\section{IMPLICAÇÕES DO PROCESSO DE INTEGRAÇÃO AOS DIREITOS HUMANOS}

Observamos do item anterior que, do ponto de vista ontológico, não há na integração econômica um benefício acertado aos direitos humanos, ainda que possa ser reconhecida a ampliação (em tese) de algumas liberdades instrumentais. O desenvolvimento de uma agenda de direitos humanos, consequentemente, não decorre de uma necessidade do projeto. Por outro lado, há espaço para a proteção de direitos humanos em comunidades econômicas regionais, embora sem uma predisposição a priori.

Ainda assim, há diversos fatores que podem contribuir para o desenvolvimento de uma agenda comunitária de defesa dos direitos humanos. A disposição e a situação política dos Estados membros, pressões provenientes da sociedade civil e/ou da comunidade internacional e a adoção de políticas estratégicas para aumento de soft power ${ }^{14}$ são alguns exemplos. Além desses, que são fatores circunstanciais (e que podemos associar à comunidade econômica como produto), há consequências jurídicas decorrentes da dinâmica econômica relacionadas ao processo de integração que podem trazer à tona questões de direitos humanos.

\footnotetext{
${ }^{14}$ Sobre isso, ver NYE, 2014, p. 6.
} 
Mesmo em acordos estritamente comerciais (isto é, sobre tarifas e comércio ou shallow integration ${ }^{15}$ ), acontecem, em decorrência desses, mudanças nos mercados envolvidos, podendo resultar em benefício para uns e, ao mesmo tempo, prejuízo para outros ${ }^{16}$. Esse tipo de consequência, aliás, acontece em todo tipo de interferência do Estado nos respetivos mercados, esteja relacionada a arranjos econômicos ou não. Uma simples mudança de regra fitossanitária pode funcionar como barreira técnica para a importação de commodities agrícolas estrangeiras e, por conseguinte, gerar desemprego em países produtores desconformes à nova regra. Em acordos econômicos, que introduzem mudanças diretamente nos mercados dos Estados partes, há um inevitável impacto nas respectivas dinâmicas econômicas, afetando ao menos alguma parcela dos indivíduos, seja para o bem, seja para o mal.

Se no resultado o mercado pode prejudicar indivíduos, é porque não há limites que lhe sejam intrínsecos, cabendo principalmente aos direitos humanos limitar, minimizar ou mesmo evitar o alcance e/ou a potencialidade dos danos. Claro, nem todo e qualquer prejuízo tem de ser evitado, o que, em última análise, seria condenar a própria existência de uma ordem econômica, atribuindo-lhe uma nocividade irreal - já que o desenvolvimento econômico também pode servir de instrumento para o desenvolvimento humano. O papel primordial dos direitos humanos, nesse sentido, é o de diretriz informadora da integração, fazendo com que esta seja implantada de maneira preferencialmente sustentável e em prol da inclusão social, evitando, de outro lado, o aumento das desigualdades, a marginalização das minorias, o abuso do poder econômico, etc., que podem acontecer na ausência de um planejamento adequado ou de um controle dos resultados em relação a essas questões.

Isso porque, como apontou Habermas (1992, p. 261-265), o sistema (econômico) possui um impulso de colonizar o "mundo da vida"17, substituindo a ação comunicativa - na qual os atos são voltados a um consenso público - pela sua ação racional-com-respeito-a-fins ${ }^{18}$ - na qual os atos são

\footnotetext{
${ }^{15}$ Enquanto "o conceito de deep integration é amplamente usado para se referir a qualquer arranjo que vá além de uma simples zona de livre comércio", uma "simples zona de livre comércio” equivale a uma shallow integration (WORLD TRADE ORGANIZATION, [201-?], p. 9).

${ }^{16}$ No exemplo da Parceria Transpacífico (TPP), diversas associações civis alertam para as consequências do acordo, como a ONG Public Citizen, segundo a qual “o TPP expandiria o modelo do acordo comercial do NAFTA que provocou nos EUA déficit comercial massivo e desemprego, pressão para redução salarial, desigualdade social sem precedentes e nova enxurrada de importados agrícolas” (PUBLIC CITIZEN, [2015?], tradução nossa).

${ }_{17}$ Marcelo Neves (2006, p. 74-75) ressalta que “A colonização do mundo da vida relaciona-se diretamente com três fenômenos de crise acima referidos: 'perda de sentido', anomia e perturbação da personalidade. Nesse sentido, a integração sistêmica intervém destrutivamente na reprodução cultural, na integração social e na socialização”.

18 "Na teoria habermasiana a diferenciação entre sistema e mundo da vida associa-se, em outro nível, à distinção entre agir comunicativo e agir racional-com-respeito-a-fins. O primeiro [...] é orientado para o entendimento intersubjetivo.
} 
voltados à satisfação dos desejos (egoístas) privados. Na ausência de mecanismos de limitação do sistema, o mundo da vida se expõe ao risco de colonização, prejudicando a ação comunicativa e, portanto, as formas de solidariedade social. Por essa razão, “a noção de crise está intimamente relacionada com a interação entre sistema e mundo da vida” (NEVES, 2006, p. 74). O direito, “como esfera de intermediação entre sistema e mundo da vida” (NEVES, 2006, p. 107), possui o papel de evitar essa crise, ou seja, de impedir a colonização do primeiro sobre o segundo, devendo, para tanto, ostentar autonomia moral "perante os meios 'poder' e ‘dinheiro”” (NEVES, 2006, p. 117), uma vez que a autodeterminação moral esteja relacionada aos direitos humanos (NEVES, 2006, p. 115-118).

Ainda que a concepção habermasiana possa ser contestada, há uma inegável relevância da ordem econômica sobre a vida dos indivíduos. De acordo com Bauman (2001, p. 11), que refuta algumas concepções de Habermas (entre elas a ideia de colonização do mundo da vida), a ordem econômica apenas dominou a totalidade da vida humana, tornando irrelevante todo o restante no que concerne à sua reprodução ${ }^{19}$. A presença da ordem econômica é, de fato, tão “esmagadora” que permeia praticamente todos os espaços da vida em sociedade, incluindo o patrimônio individual de direitos fundamentais.

Por sua vez, a teoria de sistemas sociais de Luhmann (1995, p. 8) identifica na sociedade moderna o primado da diferenciação funcional, pelo qual a principal forma de diferenciação na sociedade mundial se dá por meio de especialização de racionalidades. Essa especialização, com relação ao restante da sociedade, ocorre de maneira autopoiética, ou seja, de modo operativamente fechado (i.e., não determinada por racionalidades concorrentes), embora cognitivamente aberto (i.e. consciente das demais estruturas sociais), com autorreferência, reflexividade e reflexão (LUHMANN, 1995, p. 33-35). O sistema econômico, enquanto subsistema social autopoiético, diferencia-se pela sua racionalidade da riqueza voltada ao lucro, podendo conflitar com as demais racionalidades, como a jurídica, baseada na conformidade jurídica voltada à justiça (NEVES, 2006, p. 59-67).

Seja como sistema (Habermas), sólido perfeito (Bauman) ou subsistema social autopoiético (Luhmann), a ordem ou sistema econômico ocupa porção central na vida do indivíduo e da sociedade, e de modo preponderante. Conduzido por lógica e valores próprios, ela compete a todo instante com

[...] O segundo orienta-se na busca do êxito, distinguindo-se em dois subtipos, ação instrumental e ação estratégica” (NEVES, 2006, p. 75).

19 “Não que a ordem econômica, uma vez instalada, tivesse colonizado, reeducado e convertido a seus fins o restante da vida social; essa ordem veio a dominar a totalidade da vida humana porque o que quer que pudesse ter acontecido nessa vida tornou-se irrelevante e ineficaz no que diz respeito à implacável e contínua reprodução dessa ordem” (BAUMAN, 2001, p. 11). 
outros valores individuais e sociais. Sob um ponto de vista ideológico democrático, há um interesse de evitar que as mudanças da integração limitem as liberdades fundamentais, ainda que de poucos. Isso, todavia, não implica a predisposição em tese de que arranjos econômicos desenvolvam agendas de defesa de direitos humanos. Significa apenas que as modificações introduzidas por acordos econômicos atingirão, eventualmente, a condição humana de indivíduos e de grupos, seja como uma consequência de um impulso colonizador do mercado, seja de uma insolubilidade do "supersólido" ou, ainda, da afirmação do sistema (econômico) sobre seu ambiente, prevalecendo sobre os demais subsistemas, ou mesmo sobredeterminando seus objetivos.

\subsection{IMPLICAÇÕES DA PAUTA DE DIREITOS HUMANOS NAS COMUNIDADES ECONÔMICAS}

Pensar em direitos humanos relacionados ao processo de integração é, antes de tudo, pensar nas consequências deste sobre aqueles, ou seja, pensar em como as modificações jurídicas, políticas e econômicas resultantes do estabelecimento da comunidade refletem nos direitos humanos.

Como já mencionado, a integração regional é o resultado de um processo contínuo de equalização jurídico-política em determinadas áreas. Ou seja, é, ao mesmo tempo, um produto e um processo, que compõem uma dualidade da comunidade, e são, portanto, inseparáveis, embora isso seja mais evidente sob a perspectiva de projeto (de integração) e de sua execução: a fase de união alfandegária (produto) precede a instituição de um mercado comum (produto). Nessa transição, há uma série de medidas a serem tomadas pelas partes e pela própria comunidade (processo), tais como o estabelecimento de instrumentos regulatórios do bloco, seguido pela sua implantação nos membros, com eventuais ajustes jurídicos para acomodar as novas disposições comunitárias. O produto, nesse sentido, é a forma da comunidade, enquanto o processo são as transformações que a moldam.

As transformações de uma comunidade não cessam com o atingimento de uma eventual fase final. Mesmo que esta seja alcançada, por exemplo, com o estabelecimento de um mercado comum, a manutenção da comunidade é, em si, um processo contínuo de transformação. Afinal, há no mínimo a necessidade de administrar a comunidade, que envolve reagir à dinâmica social, tanto interna quanto externa, além de inúmeros outros expedientes, como a admissão de novos membros.

Os desafios jurídicos desse processo são bastante aparentes: harmonizar disposições padronizadas entre diferentes ordens jurídicas. A dificuldade, certamente, vai além da adoção de um conjunto de regras comuns aos participantes, porque cada ordem jurídica opera por uma lógica própria, da qual emerge uma complexidade recheada de incompatibilidades com as demais. Ou seja, 
o desafio jurídico é, antes de tudo, gerir o inevitável conflito entre as ordens nacionais e a ordem comunitária. A complexidade de uma ordem faz com que as incompatibilidades possam surgir de qualquer parte do ordenamento, ou seja, sem relação temática com a disposição em conflito. É precisamente nesse ponto que questões de direitos humanos podem surgir, ainda que a integração não tenha qualquer orientação voltada aos direitos humanos, seja no processo de determinada fase, seja no projeto como um todo.

Como já vimos, o inter-relacionamento das esferas da vida, estruturadas ou não em sistemas autônomos, é inerente a todo tipo de interação social. No direito, isso reflete no inter-relacionamento de matérias. Um fato considerado em toda sua complexidade não se restringe aos recortes do direito. Ele pode, simultaneamente, dizer respeito a questões de direito privado, direito tributário e direito penal. O mesmo se aplica a fatos relacionados ao direito da integração econômica, que podem compreender questões de direitos humanos. Dada a “onipresença” da ordem econômica - presente em grande parte das relações jurídicas - bem como o status constitucional dos direitos fundamentais - que se aplicam igualmente de forma abrangente -, a interseção entre eles é certeira, intensificandose à medida que a integração se aprofunda.

A configuração jurídica do arranjo econômico, nesse caso, é relevante para indicar o nível dessas interações. O arranjo regional, até então limitado a disposições jurídicas concernentes aos Estados partes, passa a contemplar os seus nacionais. Se isso ocorrer em uma esfera jurídica distinta da nacional (isto é, na qual há um nível jurídico comunitário), haverá, para o indivíduo, duas ordens jurídicas simultâneas, compondo um verdadeiro sistema constitucional multinível. Nessa configuração é possível, senão provável, que haja colisões normativas internível, envolvendo, sobretudo, direitos fundamentais, ante o (provável) tratamento constitucional dessa matéria - que, pela ótica nacional, não pode ceder às disposições comunitárias. Dito de outra maneira, há uma predisposição para que questões de direitos fundamentais surjam em razão do processo de integração, especificamente do choque entre as ordens jurídicas nacional e comunitária, o que pode levar a discussão para dentro do arranjo comunitário.

Desse choque ao enfrentamento das questões de direitos humanos correlatos há uma certa distância a ser superada, que pode ser maior ou menor em razão do aparato jurisdicional existente tanto na comunidade quanto no Estado membro, como disponibilidade/acessibilidade à jurisdição comunitária, sistemas judiciários nacionais aptos a enfrentar o choque, mecanismos de diálogo, etc. E ainda que haja tal enfrentamento, a adoção pela comunidade econômica regional de uma postura protetiva dos direitos humanos é em si uma incógnita. 
O cenário atual, no entanto, é mais favorável à defesa dos direitos humanos do que aquele do velho regionalismo. Após mais de meio século de afirmação da proteção internacional dos direitos humanos, é razoável supor que haja na atualidade alguma consciência sobre o assunto, o que poderia explicar, em parte, o aumento dessas pautas nas comunidades econômicas. Ainda que essa suposição se mostre falsa, a experiência acumulada pelas comunidades de integração existentes ao longo das últimas décadas tem mostrado que não é possível avançar na integração sem coordenar o direito comunitário com a proteção jurídica dos direitos fundamentais que ocorre nos Estados membros. Pelo menos foi o caso, a título de exemplo, da União Europeia, onde o ingresso dos direitos humanos no vocabulário do direito comunitário se deu, originalmente, em consequência do processo de integração, para, posteriormente, serem institucionalmente incorporados pela comunidade (ou seja, como parte do produto da integração).

Em acordos de deep integration, em que as disposições vão além das questões tarifárias e comerciais, há um escopo de juridicização comunitária mais amplo que acordos de shallow integration. Consequentemente, a possiblidade de interseção entre integração e direitos humanos aumenta, gerando mais casos com questões referentes a ambas as matérias, embora não necessariamente em prejuízo ao indivíduo ou a seus direitos fundamentais. Além disso, quanto mais profunda a integração, mais a juridicização por parte da comunidade inclui matérias tradicionalmente de direito interno, eventualmente dispondo diretamente sobre o indivíduo, ou seja, gerando a ele direito e/ou dever subjetivo.

\subsection{O RECONHECIMENTO DOS DIREITOS HUMANOS NA ABERTURA NORMATIVA}

O conflito jurídico entre as ordens comunitária e estatal é uma consequência inevitável que emerge da diferença entre essas ordens e que se manifesta sob a forma de conflito normativo. Contudo, olhar apenas para as diferentes ordens normativas não é suficiente para ilustrar a tensão entre elas, já que o conflito ocorre também dentro de cada uma delas, entre normas de uma mesma ordem. Quando ocorre internamente a uma ordem jurídica, entram em cena mecanismos de direito intertemporal, técnicas de interpretação e remédios constitucionais, em busca de sua solução. Tratase de uma necessidade do próprio ordenamento, que precisa de respostas com a maior consistência possível. Quando ele ocorre entre ordens distintas, a situação é mais complexa.

Em casos sob jurisdição simultânea de duas ordens distintas, os conflitos normativos interníveis estão muito além das normas envolvidas. De fato, por trás de cada norma há um completo sistema normativo, acompanhado, por exemplo, de princípios e jurisprudência próprios, que compõe 
a unidade que dá forma ao ordenamento. Quando um mesmo caso é submetido a duas jurisdições, é possível que as respostas divirjam entre si, embora sejam consistentes perante os respectivos ordenamentos. Há, nesse caso, uma incompatibilidade sistêmica, que pode deixar o conflito sem solução. A solução final vai depender de como os ordenamentos se posicionam um perante o outro.

Tratando-se de direitos humanos, o desenvolvimento da matéria em sede de jurisdição comunitária depende do reconhecimento, por parte da comunidade econômica regional, da necessidade de avançar sobre as questões de direitos fundamentais do Estado membro. Ou seja, o pressuposto para uma análise reativa da comunidade econômica sobre questões de direitos humanos é a cognição do direito do Estado membro pela comunidade, pela qual a jurisdição comunitária reconhece a interferência entre as ordens jurídicas comunitária e nacionais. Tal pressuposto é inevitável à construção de uma jurisprudência comunitária apta a lidar com o conturbado processo de integração, na medida em que o choque entre ordens normativas é inevitável. Ou seja, o processo de harmonização normativa envolve, antes de tudo, a equalização nacional-comunitária, pela qual as ordens relacionadas precisam de alguma forma de diálogo. Considerando a centralidade do aparato jurisdicional (em especial o judicial) na solução de conflitos jurídicos, a jurisprudência, enquanto produto da atividade de interpretação do direito, é um dos motores dessa equalização.

A necessidade de diálogo entre ordens para conferir viabilidade jurídica à comunidade não estava evidente no início da pioneira das comunidades econômicas - a CECA, a exemplo do caso Stork v High Authority (EUROPEAN COMMUNITIES, 1959), cujos fatos remetem à instalação da Comunidade, em 1952. De maneira resumida, em 9/9/1952 a “Alta Comissão Aliada na Alemanha reestruturou a venda de carvão no Vale do Ruhr [...]. Como resultado, grande parte das mineradoras das minas de carvão no Vale do Ruhr se organizarem em seis agências independentes” (EUROPEAN COMMUNITIES, 1959, p. 20, tradução nossa) ${ }^{20}$, as quais estabeleceram novo patamar para venda direta, de 6.000 para 48.000 toneladas, prejudicando o autor, que deixou de ser revendedor direto. A ação buscava a anulação de uma decisão da Alta Autoridade que autorizou as medidas adotadas pelas agências, lícitas perante o direito comunitário, mas não perante o direito alemão, por formação de cartel. O Tribunal de Justiça da CECA rejeitou o pedido do autor, argumentando, entre outras razões, pela impossibilidade de analisar violações de princípios do direito alemão:

\footnotetext{
20 Tradução livre de: “Order No 20 of the Allied High Commission in Germany of 9 September 1952 (Official Journal of the Allied High Commission, p. 1901 et seq.) reorganized the sale of coal in the Ruhr. As a result, most of the collieries in the Ruhr coalfield formed themselves into six independent joint selling agencies under the control of an organization known as the Gemeinschaftsorganisation Ruhrkohle GmbH (GEORG)".
} 
Pelo artigo 8 do Tratado, exige-se da Alta Autoridade apenas a aplicação do direito comunitário. Ela não é competente para aplicar o direito nacional dos Estados membros. Similarmente, pelo artigo 31, exige-se do Tribunal apenas assegurar que, na interpretação e aplicação do Tratado e das regras estabelecidas para sua implementação, o direito seja observado. Não é normal exigir dele decidir sobre dispositivos do direito nacional. Consequentemente, a Alta Autoridade não possui poderes para examinar um argumento que afirme que, quando ela adotou sua decisão, violou princípios do direito constitucional alemão (particularmente os artigos 2 e 12 da lei fundamental). (EUROPEAN COMMUNITIES, 1959, p. 24, tradução nossa) ${ }^{21}$

Nessa decisão, o Tribunal ainda reputava o direito comunitário isolado do direito nacional, impedindo diálogo entre as ordens. Em 1963, no paradigmático caso van Gend en Loos vs Administração fiscal, o Tribunal passou a admitir diálogo entre as ordens, particularmente quanto aos efeitos do direito comunitário na esfera nacional:

O TRIBUNAL DE JUSTIÇA, pronunciando-se sobre o pedido que lhe foi submetido, a título prejudicial, pela Tariefcommissie, por decisão de 16 de Agosto de 1962, declara:

1) $\mathrm{O}$ artigo $12 .^{\circ}$ do Tratado que institui a Comunidade Económica Europeia produz efeitos imediatos e cria na esfera jurídica dos particulares direitos individuais que os órgãos jurisdicionais nacionais devem salvaguardar; [...] (EUROPEAN COMMUNITIES, 1963, p. 215, grifo do autor)

Com isso, o Tribunal passou a apreciar a interação entre as ordens comunitária e nacionais. Consequentemente, passou também a ter de lidar com conflitos entre as duas esferas. Em 1970, os direitos humanos foram reconhecidos como diretriz de interpretação no caso 11/70 (Internationale Handegeselschaft), de 1970, "no qual o Tribunal entendeu que o respeito aos direitos humanos faz parte dos princípios gerais do direito comunitário protegido pelo Tribunal de Justiça” (DOUGLASSCOTT, 2011, p. 649) ${ }^{22}$.

Quanto mais profunda a integração, mais as questões comunitárias avançam sobre as questões "tradicionalmente" nacionais, o que amplia a possibilidade de conflito intersistêmico ${ }^{23}$. Considerando que o avanço na integração depende de soluções razoavelmente satisfatórias para as partes (Estados e comunidade), não há como se furtar ao conhecimento das ordens jurídicas

\footnotetext{
${ }^{21}$ Tradução livre de: “(a) Under Article 8 of the Treaty the High Authority is only required to apply Community law. It is not competent to apply the national law of the Member States. Similarly, under Article 31 the Court is only required to ensure that in the interpretation and application of the Treaty, and of rules laid down for implementation thereof, the law is observed. It is not normally required to rule on provisions of national law. Consequently, the High Authority is not empowered to examine a ground of complaint which maintains that, when it adopted its decision, it infringed principles of German constitutional law (in particular Articles 2 and 12 of the Basic Law)”.

${ }^{22}$ Tradução livre de: "Case 11/70 Internationale Handelsgesellschaft [1970] ECR 1125, in which the Court held that respect for human rights forms an integral part of the general principles of Community law protected by the Court of Justice.” (DOUGLAS-SCOTT, 2011, p. 649)

${ }^{23}$ Sistema sem acepção luhmanina; no caso, como sinônimo de ordenamento.
} 
envolvidas, bem como ao desenvolvimento de uma jurisprudência consistente no tratamento dos conflitos emergentes.

\section{CONSIDERAÇÕES FINAIS}

Que implicações a concepção do produto e do processo das comunidades econômicas regionais tem sobre os direitos humanos? Essa questão foi aqui investigada a partir da própria concepção dos objetivos imediatos e mediatos da integração econômica, trazendo exemplos que ilustram um rol de possibilidades analíticas de conceber a relação entre essa integração e os direitos humanos.

A primeira parte se focou no produto da integração econômica, provando que ele por si só não traz benefício certo aos direitos humanos, de um ponto de vista ontológico. Foi investigada a própria noção de integração de mercados como um valor buscado diretamente pela integração econômica. Demonstramos que os possíveis aumentos dos direitos dos indivíduos podem ocorrer ou não nesse processo de integração, a depender do controle de medidas que podem influenciar negativamente os direitos humanos; ou mesmo do reforço de medidas que tenham potencial benéfico, mas que dependem de reforços de política para levar ao aumento de direitos. No mesmo sentido, as medidas de performance da integração regional foram questionadas diante de alguns exemplos práticos de fracassos e sucessos em promoção de direitos humanos. Foi possível perceber que o foco único na integração por parte das comunidades econômicas regionais leva as medidas a não serem efetivas em termos de direitos humanos, mesmo quando direcionadas a esses direitos, caso fiquem absolutamente submetidas às prioridades do arranjo institucional.

Na segunda parte, o artigo explorou a relação entre os arranjos econômicos e as esferas da vida, que se observa no caso do processo de integração das comunidades regionais. A implementação de direitos humanos deve necessariamente passar pelo desenvolvimento econômico - por isso a posição privilegiada do sistema de integração para levar em conta também o tema de direitos humanos em sua agenda. Contudo, quando se fala em sistema como foco de análise, fica visível a impossibilidade de desatrelar o arranjo econômico de todas as outras áreas da vida. Assim, durante o processo da integração, nos conflitos interníveis de ordenamentos jurídicos, há escolhas eventuais sobre direitos humanos. Isso ficou claro a partir dos exemplos de decisões jurisdicionais de comunidades econômicas: eventualmente, decide-se aplicar comunitariamente as regras de direitos humanos, mesmo que de nível nacional, no qual o tema é relevante ao plano da vida. 
Este artigo procurou então esclarecer dois pontos sobre os quais outras possíveis reflexões sobre a promoção dos direitos humanos pelas comunidades econômicas regionais podem ser construídas. Primeiro, ainda que não haja uma predisposição, desde sua constituição, de que comunidades econômicas regionais se voltem para a promoção de direitos humanos, há espaço para essa promoção de forma indireta na prática do objetivo direto de integração. Ainda mais: o processo de integração tem, eventualmente, consequências para os direitos humanos, seja de forma planejada ou não. Portanto, a proteção dos direitos humanos fica em cheque diante de medidas integracionistas que não levem em conta possíveis consequências colaterais da aparentemente boa integração econômica, que por si só não leva necessariamente à melhoria dos direitos humanos uma vez alcançado o seu produto.

Para discutir quais as melhores vias de proteção aos direitos humanos, futuras investigações poderão partir dessas conclusões para investigar o estabelecimento de mecanismos específicos de promoção e proteção de direitos humanos dentro das comunidades econômicas regionais. Em última análise, com base nesses elementos, é possível passar à comparação do conjunto das comunidades econômicas com os sistemas de promoção estabelecidos em organizações políticas internacionais governamentais, e eventualmente identificar diferenças de efetividade entre os dois tipos de arranjo em relação à proteção aos direitos humanos.

\section{REFERÊNCIAS}

APPUNN, Kerstine. The history behind Germany's nuclear phase-out. Clean Energy Wire. Berlin, 24 jul. 2015. Disponível em: <https://goo.gl/e49c3m>. Acesso em: 5 dez. 2015.

BAUMAN, Zygmunt. Modernidade líquida. Tradução Plínio Dentzien. Rio de Janeiro: Zahar, 2001. 257 p.

BRASIL. Ministério das Relações Exteriores. Integração Regional: Mercosul [20--]. Disponível em: <https://goo.gl/Lgle49>. Acesso em: 1 dez. 2015.

COMESA - EAC - SADC TRIPARTITE; IGAD. Linking up Eastern and Southern Africa Sustainable Economic Development. In: COMESA - EAC - SADC TRIPARTITE; IGAD. Infrastructure Development Conference. Nairobi: Kenyatta International Conference Centre, 2010. p. 1-51. Disponível em: <https://goo.gl/hEGi4G>. Acesso em: 21 dez. 2015.

COMESA-EAC-SADC TRIPARTITE. COMESA-EAC-SADC Tripartite Framework: State of Play - Report by the Chair of the Tripartite Task Force. Jul. 2010. Disponível em: <https://goo.gl/DL4ZvI>. Acesso em: 21 dez. 2015. 
DOUGLAS-SCOTT, S. The European Union and Human Rights after the Treaty of Lisbon. Human Rights Law Review, v. 11, n. 4, p. 645-682, 28 nov. 2011. Oxford University Press (OUP). Disponível em: <http://dx.doi.org/10.1093/hrlr/ngr038>. Acesso em: 21 dez. 2015.

EUROPEAN COMISSION. Nuclear Energy: Safe nuclear power [2016]. Disponível em: $<$ https://goo.gl/6DsenM>. Acesso em: 9 dez. 2015.

EUROPEAN COMMUNITIES. Case $n^{\circ}$ 26/62. NV Algemene Transport- en Expeditie Onderneming van Gend \& Loos v. Netherlands Inland Revenue Administration. Relator: Judge Hammes. Luxemburgo, 5 Feb. 1963. ECLI:EU:C:1963:1. Disponível em: <https://goo.gl/b9oKi7> e (versão em português) em: <https://goo.gl/KQxTmO>. Acesso em: 18 jan. 2016.

EUROPEAN COMMUNITIES. Court of Justice of the European Communities. Case $n^{0} 1 / 58$. Friedrich Stork \& Cie v. High Authority of the European Coal and Steel Community. Relator: Judge Riese. Luxemburgo, 4 jan. 1959. ECLI:EU:C:1959:4. Disponível em: <https://goo.gl/Qbsepx>. Acesso em: 18 jan. 2016.

FAO. IGAD Early Warning and Food Information System for Food Security: Project Findings and Recommendations. Rome: United Nations, 1997. Disponível em: <https://goo.gl/bso1dJ>. Acesso em: 12 dez. 2015.

FAWCETT, Louise. Regionalism in Historical Perspective. In: FAWCETT, Louise; HURRELL, Andrew (Ed.). Regionalism in World Politics: Regional Organization and International Order. $1^{\text {st }}$ ed. reprinted. Oxford: Oxford University, 2003. p. 9-36.

HABERMAS, Jürgen. Teoría de la acción comunicativa, II: crítica de la razón funcionalista. Tomo 2. $1^{\text {a }}$ ed. $2^{\text {a }}$ reimp. Madrid: Taurus Humanidades, 1992.

IAEA. Chernobyl Nuclear Accident. 2015. Disponível em: <https://goo.gl/5zRXkO>. Acesso em: 5 dez. 2015.

IAEA. Fukushima Nuclear Accident. 2016. Disponível em: <https://goo.gl/NFV9by>. Acesso em: 5 dez. 2015.

IAEA. INES: The International Nuclear and Radiological Event Scale [20--]. Disponível em: $<$ https://goo.gl/8HN0ce>. Acesso em: 5 dez. 2015.

IDDRSI. About IDDRSI. 26 Feb. 2015. Disponível em: <https://goo.gl/ZlVhDK>. Acesso em: 21 dez. 2015.

IGAD. Agreement Establishing the Inter-Governmental Authority on Development, 21 March 1996. IGAD/SUM-96/AGRE-DOC. Nairobi, 1996. Disponível em: <https://goo.gl/OoxoF0>. Acesso em: 18 jan. 2016.

IGAD. About us. 9 Jan. 2010. Disponível em: <https://goo.gl/uQ1nJo>. Acesso em: 9 dez. 2015.

IGAD. Annual Report 2007. IGAD [2008]. 83 p. Disponível em: <https://goo.gl/gon0o9>. Acesso em: 20 dez. 2015. 
IGAD. IGAD Drought Disaster Resilience and Sustainability Initiative (IDDRSI): The IDDRSI Strategy. Jan. 2013. Disponível em: <https://goo.gl/eC4JOp>. Acesso em: 20 dez. 2015.

LUHMANN, Niklas. Social Systems. Tradução John Bednarz Jr. Stanford: Stanford University, 1995.

MCCORMICK, John; OLSEN, Jonathan. The European Union: Politics and policies. $5^{\text {th }}$ ed. Boulder: Westview, 2014. 374 p. (e-book)

MERCOSUL. Acordo RMI n ${ }^{0}$ 13, de 06 de dezembro de 2002. Acordo sobre Residência para Nacionais dos Estados Partes do Mercosul. Ata $\mathbf{N}^{\mathbf{0}}$ 02/2002 da XII Reunião de Ministros de Interior. Salvador, 8 nov. 2002a. Disponível em: <https://goo.gl/YCgLju>. Acesso em: 18 jan. 2016.

MERCOSUL. Acordo RMI n ${ }^{0}$ 14, de 06 de dezembro de 2002. Acordo sobre Residência para Nacionais dos Estados Partes do Mercosul, Bolívia e Chile. Ata No 02/2002 da XII Reunião de Ministros de Interior. Salvador, 8 nov. 2002b. Disponível em: <https://goo.gl/zEit20>. Acesso em: 18 jan. 2016.

NALDI, Gino J. Interim measures of protection in the Africa system for the protection of human and peoples' rights. African Human Rights Law Journal [Pretoria], v. 2, n. 1, p. 1-10, 2002. Disponível em: <https://goo.gl/7gDQSV>. Acesso em: 18 jan. 2016.

NEVES, Marcelo. Entre Têmis e Leviatã: uma relação difícil. São Paulo: Martins Fontes, 2006. 354 p.

NUCLEAR ENERGY INSTITUTE. Fukushima, Chernobyl and the Nuclear Event Scale. 2011. Disponível em: <https://goo.gl/g8cZYC>. Acesso em: 5 dez. 2015.

NYE, Joseph S. Soft Power: The Means to Success in World Politics. New York: Public Affairs, 2014.

PUBLIC CITIZEN. Trans-Pacific Partnership (TPP): More Job Offshoring, Lower Wages, Unsafe Food Imports [2015?]. Disponível em: <http://www.citizen.org/TPP>. Acesso em: 4 nov. 2015.

ROGERS, Simon. Nuclear power plant accidents: Listed and ranked since 1952. The Guardian. Londres, 18 mar. 2011. Disponível em: <https://goo.gl/lXBBap>. Acesso em: 5 dez. 2015.

SEN, Amartya. Desenvolvimento como liberdade. São Paulo: Companhia das Letras, 2000. 410 p.

UNESCO. Desertification [201-?]. Disponível em: <https://goo.gl/nDAFyT>. Acesso em: 9 jul. 2016.

UNIÃO EUROPEIA. Tratado Euratom Versão Consolidada. Luxemburgo: Serviços das Publicações da União Europeia, 2010. 112 p. Disponível em: <https://goo.gl/6sjRjA>. Acesso em: 18 jan. 2016. 
VILJOEN, Frans. International Human Rights Law in Africa. $2^{\text {nd }}$ ed. Oxford: Oxford University, 2012. $622 \mathrm{p}$.

WORLD FOOD PROGRAMME. Horn of Africa Crises [2016?]. Disponível em: <https://goo.gl/XhWkdr>. Acesso em: 18 jan. 2016.

WORLD TRADE ORGANIZATION. World Trade Report 2011. The WTO and preferential trade agreements: From co-existence to coherence. World Trade Organization [201-?]. Disponível em: $<$ https://goo.gl/IF9oP0>. Acesso em: 9 jul. 2016.

Marina Feferbaum

Doutora e Mestre em Direito pela Pontifícia Universidade Católica de São Paulo (PUC-SP). Coordenadora da área de Metodologia de Ensino da FGV Direito SP (São Paulo, SP, Brasil). E-mail: marina.feferbaum@fgv.br 